\title{
Recommandation de la Société suisse de psychiatrie et psychothérapie en vue de la votation générale TARMED
}

Décidée par le Comité, l’Assemblée des délégués et la CPT (7 février 2002)

Ne manquez surtout pas de participer à la votation. Mais attendez le 21 février 2002 pour déposer votre bulletin de vote!

Parce que: le 12 février 2002 nous allons débattre d'une erreur de calcul déterminante qui s'est produite dans l'établissement de la version 1.1, objet de la votation. Tout de suite après le 12 février 2002, nous communiquerons par lettre aux membres de la SSP le résultat de la discussion.

1. Si l'erreur de calcul est corrigée, la recommandation de vote sera clairement OUI (aux 3 questions);

2. Si l'erreur de calcul n'est pas corrigée le 12 février 2002, nous recommandons:

- de ne pas voter "non",

- d'envoyer un bulletin blanc (pour les 3 questions).
Motifs

- Nous ne sommes pas d'accord avec la version 1.1 (non corrigée) du TARMED. Toutefois, la votation concerne la version 1.1 plus le concept de reengeneering 2. dans lequel, d'ici le début de l'année 2003, les valeurs clés importantes pour nous seront réévaluées. Il se pourrait que le travail en cabinet de psychiatrie trouve ainsi dans le tarif une image plus conforme à la réalité. Considérant l'évolution de ces deux dernières années, nous voyons la possibilité d'exploiter ce processus dynamique. Nous persévérons dans nos exigences.

- Dans les circonstances actuelles, un refus du TARMED entraverait la capacité d'action politique du corps médical.

Deutsch erschienen in Nr. 8/2002 